\title{
The Middle Palaeolithic Assemblage with Bahari Technique from the Site 21b in Deir el-Bahari (Western Thebes), Upper Egypt
}

\author{
Barbara Drobniewicz $^{a}$ and Bolesław Ginter ${ }^{b}$
}

\begin{abstract}
In the I970s, the authors of this paper explored the Site 21b, situated in the north-western fringe of the Deir el-Bahari Valley, in the Theban Massif (Upper Egypt). Based on the significant variability in the state of preservation of artefacts' surfaces, six series of artefacts were identified, corresponding to the Middle Palaeolithic and Pre-Dynastic assemblages. The most detailed analysis was performed for the inventory of the series 2 , which was ascribed to a previously unknown industry with the Levallois technique and Mousterian discoidal cores. This industry is also characterised by an occurrence of a specific manner of obtaining flakes from globular and thick, flattened, lens-like nodules, abundantly occurring in the local Lower Eocene limestone. This manner of flake production was called the Bahari technique. Due to the occurrence of sidescrapers, Mousterian points, denticulated and notched pieces, the chronology of this series was determined as Middle Palaeolithic.
\end{abstract}

KEY-WORDS: Theban Hills, Middle Palaeolithic, Bahari technique

\section{INTRODUCTION}

In 1975 and 1976 , the authors of this paper, at that time active researchers at the Institute of Archaeology, Jagiellonian University in Cracow, conducted an archaeological survey on the fringe of the Deir el-Bahari Valley, in the area of the Theban Gebel (Fig. I). These studies were carried out within a scholarship granted by the Egyptian Government and were included into the so-called Deir el-Bahari Project executed under the auspices of the Polish Centre of Mediterranean Archaeology, University of

a Institute of Archaeology, Jagiellonian University, Gołębia Street II, 3I-007 Cracow, Poland; e-mail: barbara.drobniewicz@gmail.com; ORCID: 0000-0002-0524-232X

$b$ Institute of Archaeology, Jagiellonian University, Gołębia Street II, 3I-007 Cracow, Poland; e-mail: bolgint38@wp.pl; ORCID: 0000-0001-5072-075X 
64 Barbara Drobniewicz and Bolestaw Ginter

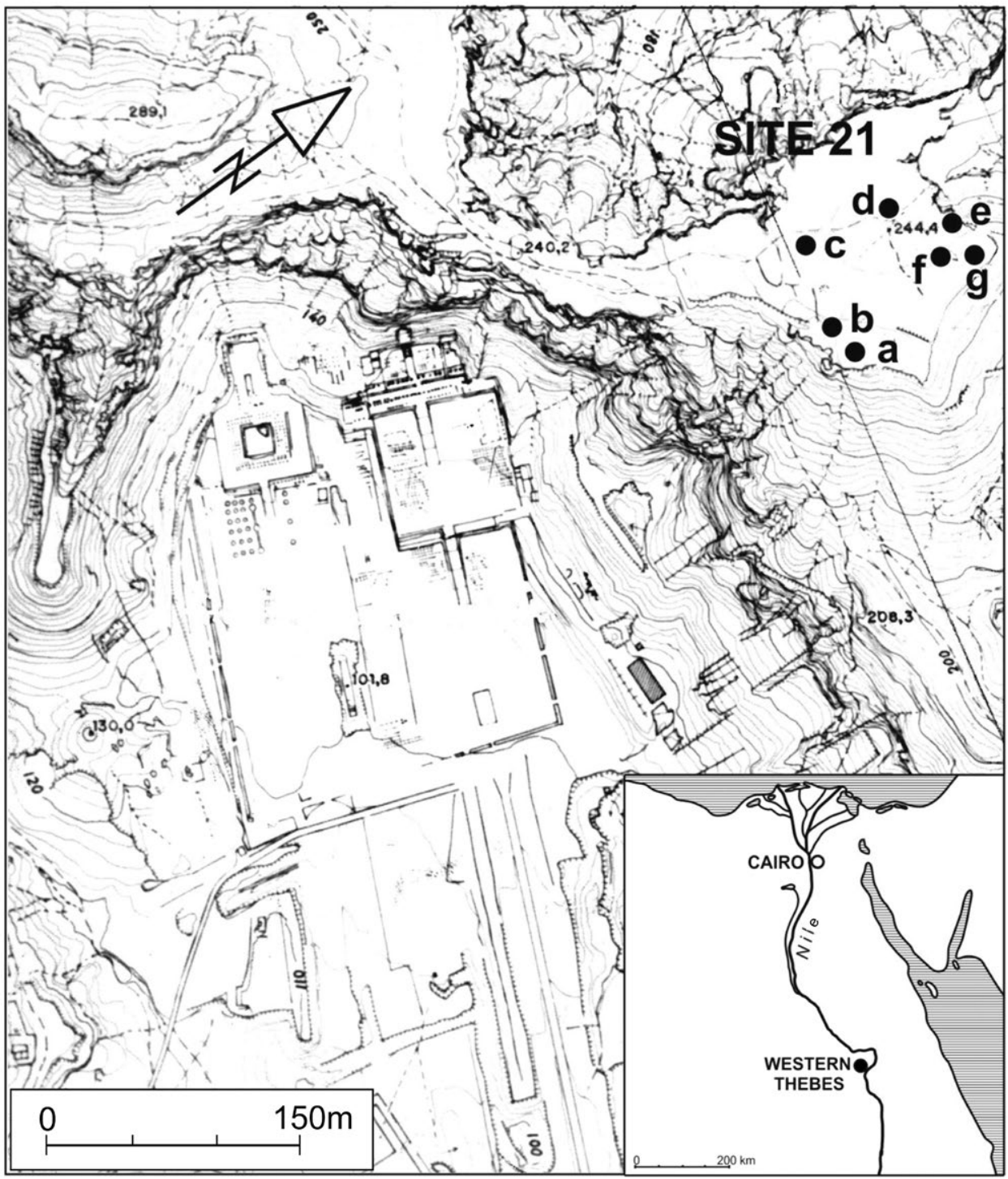

Fig. I. Topography of the Site 21 in the context of the Deir el-Bahari Valley. Graphic design: The Egyptian Antiquities Organization with changes by U. Socha. 
The Middle Palaeolithic Assemblage with Bahari Technique from the Site 21b... $\mid 65$

Warsaw. The Project aimed at tracing the process of inhabiting the valley itself as well as its closest surroundings since the prehistoric times until the Dynastic Period, with particular attention paid to the times preceding the latter. Submitting this paper to be published in the Jubilee Book dedicated to Professor Michał Kobusiewicz should be seen as an expression of our great fellow feeling for our colleague and friend and respect for his outstanding achievements in studies upon the prehistory of NorthEastern Africa.

As we know, an interest in the prehistory of the Western Thebes region has got a long history; since its beginnings reach as far back as to the second half of the igth century. The first expeditions in search of lithic materials and their interpretations were the work of such scholars as A. Arcelin (Arcelin 1869: 136-407; I870: 155-189) and A. Pitt-Rivers (Pit-Rivers I882). Also noteworthy are systematic field studies carried out at the end of the 19th century and beginning of the 2oth century by G. Schweinfurth, who, apart from collecting prehistoric assemblages, distinguished and localised a number of archaeological sites, and created a topographic map of them (Schweifurth 1903: 798-838). In the 1930s, R. Cottevieille-Giraudet brought to light the issue of the occurrence of prehistoric sites at various altitudes on the Theban Gebel, connecting this phenomenon with the differentiation of their age. He was also the first researcher who identified the Lower Palaeolithic artefacts from this region (Cottevieille-Giraudet 1933). At the same time K. S. Sandford and W. J. Arkell presented their concept of the occurrence of four major Pleistocene alluvial terraces in this part of the Nile Valley, distinguishing the Middle Palaeolithic artefacts amongst other flint materials (Sandford and Arkell 1933). Studies upon the region under scrutiny became more intense once again in the 1960s, and even more in the I970s. This was associated with an activity of the French-Egyptian expedition headed by Ch. Desroches-Noblecourt, with the participation of F. Debono, which mostly aimed at searching for graffiti on rocks as well as identification and topographic location of prehistoric sites in the area of the Theban Hills (Debono 1972). A major role in shaping the current viewpoints on the geology and prehistory of this part of Egypt was played by field research conducted within the activity of the Combined Prehistoric Expedition headed by F. Wendorf, R. Said and R. Schild. Their numerous publications addressing the issues of stratigraphy, age and dynamics of the Pleistocene sediments origins, evolution of the Nile Valley, as well as identification of new taxonomic units and development of the Palaeolithic cultures are still current, constituting an excellent point of reference for further studies (Said et al., 1970; Said 1975).

In the winter season of 1973/74, the researchers of the Institute of Archaeology, Jagiellonian University in Cracow, J. K. Kozłowski and J. Śliwa, commenced a field survey which led to the recognition of the geology, stratigraphy and topography of the Deir el-Bahari Valley and its closest surroundings. They also recorded a dozen or so concentrations of flint and stone materials of various ages (Drobniewicz et al., I976: II-26). 
In the following season, in which the authors of this paper joined the expedition, a few selected sites were explored entirely or partly, and other concentrations of artefacts visible on the ground surface were recognised. Assemblages found within those concentrations varied in terms of chronology and cultural affiliation, and were dated within wide time frames from the Middle Palaeolithic until the Dynastic Period (Heflik and Kozłowski 1977: 7-30).

\section{THE SITE 21}

Our particular attention was drawn by the Site 21, situated in the north-western part of the valley fringe, lying at an altitude of $c .244 \mathrm{~m}$ a.s.l., and $c .150 \mathrm{~m}$ above the valley bottom. The site embraces a fragment of a widespread structural platform of the Theban limestone of the Lower Eocene age, formed by erosion processes (Drobniewicz and Ginter 2019: 106; Fig. I). Its surface is covered with a thin layer of silty sands of yellowish colour, beneath which there occurs the limestone bedrock cut through by tectonic and erosive cracks. Within the boundaries of the site a few quite well isolated concentrations of flint artefacts were discovered (Fig. 2), amongst which one, namely the concentration no. $21 \mathrm{~b}$, was entirely explored. This feature was almost oval in shape and had dimensions of $c .30 \times 20$ meters. Artefacts found within it lay exclusively on its surface; therefore, the exploration

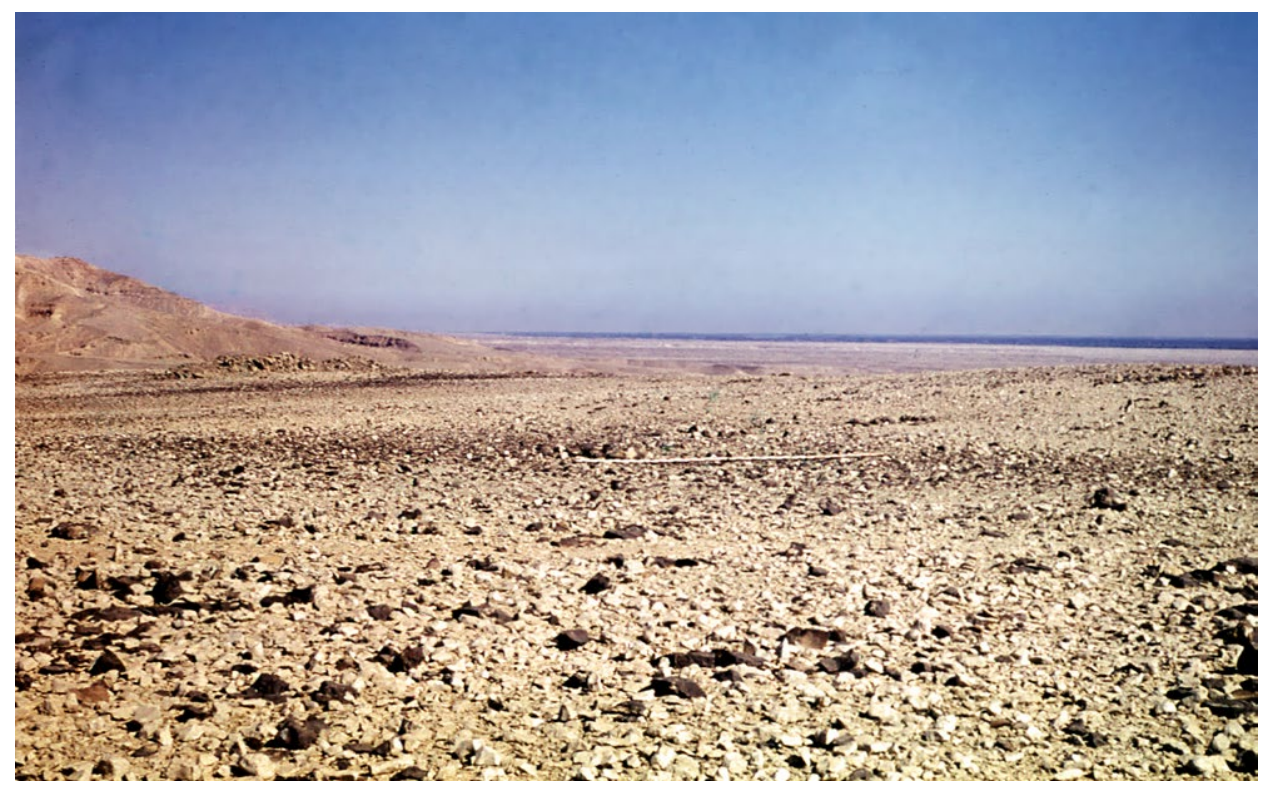

Fig. 2. Deir el-Bahari. The Site 21b, view from the west. Photo: B. Ginter. 
A -1

- -2

- -3

- -4

- -5

- -6

$-1-7$

- -8

v -9

- -10

$\boldsymbol{T}-11$

$\times-12$

. -13

$\diamond-14$

• -15

$0-16$

- -17

- -18

- -19

- 20
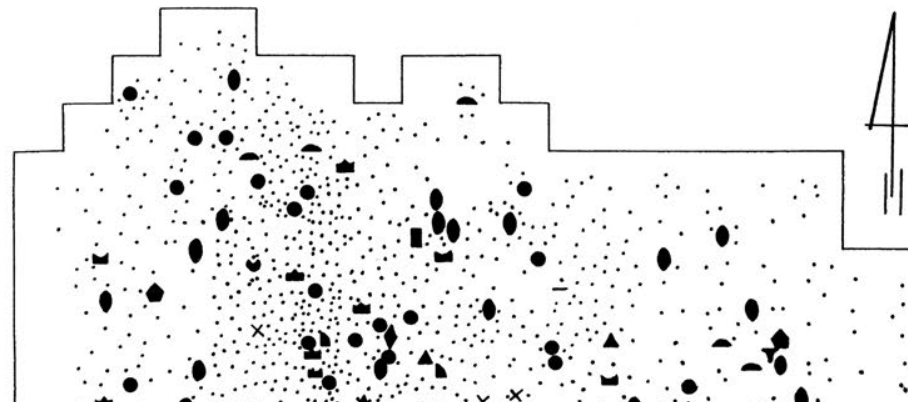

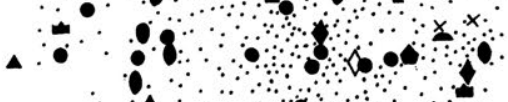
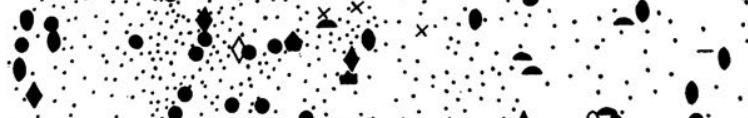

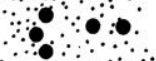

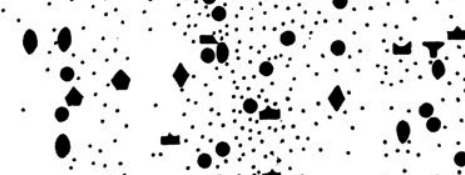

i

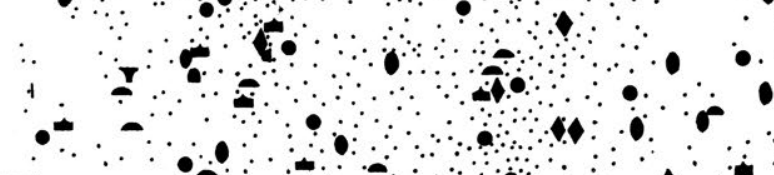

$\therefore$

$-$

080

$\therefore \therefore$ :

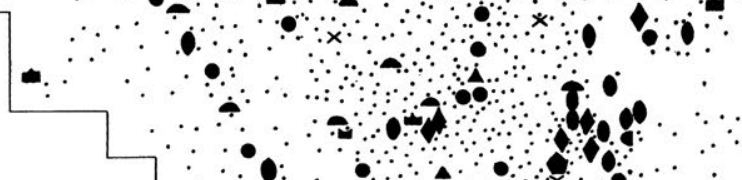

$\because \quad 0$ ب

Fig. 3. Deir el- Bahari.

Spatial distribution of artefacts at the Site 21b, Series 2:

I - Mousterian points;

Io - Bifaces;

2 - Sidescrapers;

3 - Denticulated tools;

I I - Adzes (cleavers);

I 2 - Undetermined;

I 3 - Debitage;

I 4 - Levallois precores;

5 - Endscrapers;

6- Knives;

7 - Flakes and blades with retouches;

8 - Flakes with flat retouches;

I 5 - Levallois cores;

I 6 - Non-Levallois precores;

I 7 - Discoidal cores;

I 8 - Bahari cores;

I9 - Flake cores;

20 - Blade cores.

$5 m$

Graphic design: U. Socha. 
was reduced to gathering them thoroughly, preceded by recording the position of the most important specimens (cores and tools) in a two-dimensional coordinate system, while less significant materials were captured within a network of squares superimposed on the investigated area (Fig. 3).

Amongst the assemblage of over ten thousand of knapped stone artefacts, the investigators at first identified three series of artefacts (Drobniewicz et al., 1976: 24), and after exploration of the further part of this concentration, a total of six series of artefacts were distinguished, corresponding with taxonomic units varied in terms of their chronology and cultural affiliation. With regard to the planigraphy, the individual series of artefacts overlapped one another, which made it impossible to separate them on spatial grounds. Due to this, we decided to perform a selection based on the nature and state of preservation of the artefacts surfaces, taking into consideration their highly variable and relatively distinguishable degree of damage, polishing or patination, as well as the colour of patina and the state of preservation of their edges. Employing a distinctive state of preservation as the major criterion allowed us to distinguish six assemblages significantly differing one from another in terms of both techniques of preparation and exploitation of cores, as well as an occurrence of particular types of tools and their frequencies.

\section{Series 1}

Artefacts of the Series 1 are characterised by strongly damaged, weathered surfaces, smoothed edges and a thick layer of patina. Their colour is dark orange to reddish. Amongst cores and debitage the Levallois technique prevails $(\mathrm{IL}=32)^{1}$, reduced almost exclusively to production of flakes, and absolutely lacking points. Unretouched Levallois tools are considerably more frequent than retouched ones (ILty $=79$ ), with predominant sidescrapers and an occurrence of an almond-shaped, slightly elongated and asymmetric biface. We believe that this series represents the Middle Palaeolithic phase of the Acheulean Culture with abundantly developed Levallois technique.

\section{Series 2}

The Series 2 was identified based on the occurrence of a specific, thick patina, deep red in colour (Fig. 4). This patina was not the only unique element characterising this series. It was also distinguishable from other assemblages due to an extremely interesting technique of core exploitation, named by the authors as the Bahari technique. The spatial distribution of artefacts is illustrated in Fig. 3. The Series 2 is considered the most significant and is the major subject of our paper, and a detailed description will be given below, following the discussion of all the other series.

1 All indices given in this paper are quoted after Bordes, F. 1953. Essai de Classfication des industries "mousteriennes". Bulletin de la Société prehistoriqué française: 50: 457-466. 

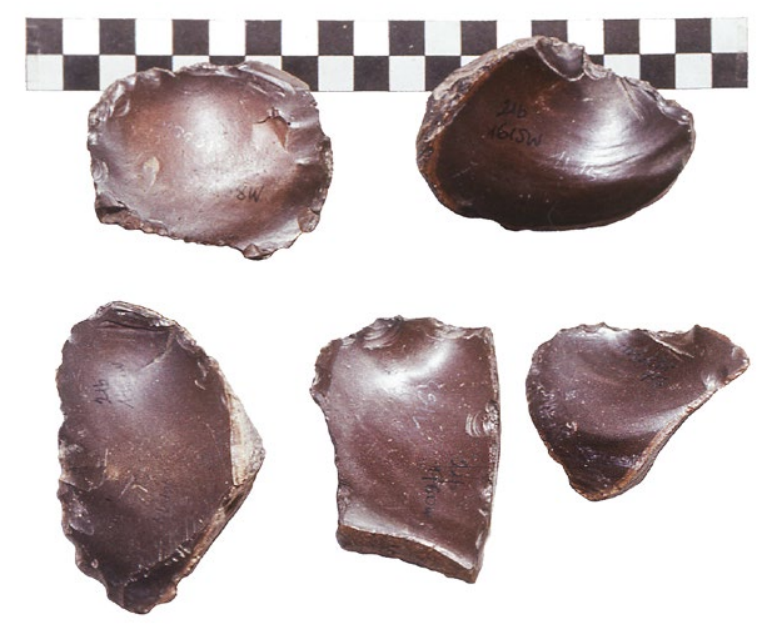

Fig. 4. Deir el-Bahari, the Site 21b. Bahari cores. Photo: B. Ginter.

\section{Series 3 and 4}

Surfaces of artefacts of the Series 3 and 4 are smooth, opaque and covered with patina, the layer of which is not very thick. The colour of the patina is various shades of beige (Series 3), or beige-orange changing into gently reddish (Series 4) with visible blackish varnish. Edges of the artefacts are slightly smoothed, so are the ridges between the scars. Both of these series share many common traits, in respect of both toolset as well as flaking techniques. The Levallois index is medium high ( $\mathrm{IL}=\mathrm{I} 2$ and $\mathrm{I} 6$, respectively), with a visible predominance of flakes and flake cores, but with a high contribution of points and blades, and a very low frequency of Mousterian discoidal cores and flakes detached from them. A relatively numerous group of artefacts is represented by a specific variant of Levallois cores typical of the so-called Nubian Mousterian distinguished in the Wadi Halfa region (Marks 1968a). With regard to both of the series under discussion, unretouched Levallois tools prevail in number over the retouched ones (ILty $=6 \mathrm{I}$ and 78 , respectively). The latter are represented mainly by sidescrapers of various types, denticulated and notched pieces, with a small contribution of endscrapers and few burins. Noteworthy is the occurrence of a single biface within the Series 3, which has got its closest analogues in the Mousterian assemblages with Levallois technique related to the above-mentioned Nubian Mousterian from the borderland between Egypt and Sudan.

\section{Series 5}

The Series 5 comprises artefacts of smooth and slightly shiny surfaces, covered entirely with thin black desert patina; the edges of the artefacts are very weakly smoothed. The Levallois technique is visible though poorly manifested $(\mathrm{IL}=4)$, whereas, the technique employing the Mousterian discoidal core is very strongly accentuated, which is legible in both cores as well as debitage. The blade technique also played a significant 
role in this series (Ilam $=17$ ), with a visible predominance of single platform cores over the double platform ones and cores with changed orientation. The flake technique, however, dominated, and was recorded in all its variants. In spite of the low technical index, the Levallois typological index is quite high due to a relatively high contribution of Levallois flakes, blades and points (Ilty $=4 \mathrm{I}$ ). Retouched tools are represented mostly by lateral, transversal and oblique sidescrapers, denticulated and notched pieces, as well as numerous endscrapers and burins of various types. Noteworthy is a relatively high index of the Upper Palaeolithic tools (IPs = 27). While searching for assemblages of similar traits, the authors' attention was drawn by materials discovered in the Wadi Halfa region and described by A. E. Marks, who used them as providing the grounds for distinguishing a new cultural unit, named the Khormusan Culture (Marks I968b).

\section{Series 6}

The Series 6, undoubtedly much later than those discussed above, comprises artefacts with "fresh" surfaces, practically not affected by patina, which in general has not changed the colour of the processed flint concretions. If a patina occurs, its colour is grey-beige and it covers only fragments directly exposed to the activity of atmospheric factors. The edges of these artefacts are sharp, without any traces of smoothing. This series is represented exclusively by flake cores of various types, including cores with changed orientation, as well as quite numerous blade cores, with a small contribution of cores for blades and flakes. A frequent phenomenon was the reutilisation of cores and precores from older series. Tools are not very frequent ( $3 \%$ of all artefacts), with a predominance of denticulated and notched pieces, and a significantly lower contribution of endscrapers and burins. They are rather large and roughly elaborated, which is typical of workshop sites. In terms of their state of preservation and the nature of cores and debitage they mostly resemble the Pre-Dynastic assemblages, especially those of the Naqada Culture, accompanying a great number of sites of this cultural unit in the foothills of the Theban Hills, close to the boundary of the present cultivation zone. The series in question is most likely a relic of a flint workshop of the above-mentioned culture.

\section{Artefacts of the Series 2}

In our opinion, the most interesting of these six groups is the above-mentioned series 2 . This was distinguished based on the characteristic thick patina of dark deep red colour, sometimes changing into reddish-purple (Fig. 4). Surfaces of the artefacts of this series are very smooth, strongly polished and shiny. The edges are blunt, smooth and rounded. In cavities, traces of black desert varnish are noticeable.

Raw materials used for production of the tools of this series were flint nodules, mostly of large dimensions, abundantly occurring in the local Lower Eocene limestone of the Theban Massif. They were easily accessible, lying in large numbers over the surfaces of erosion planes, as well as within sediments covering the slopes of the Deir 


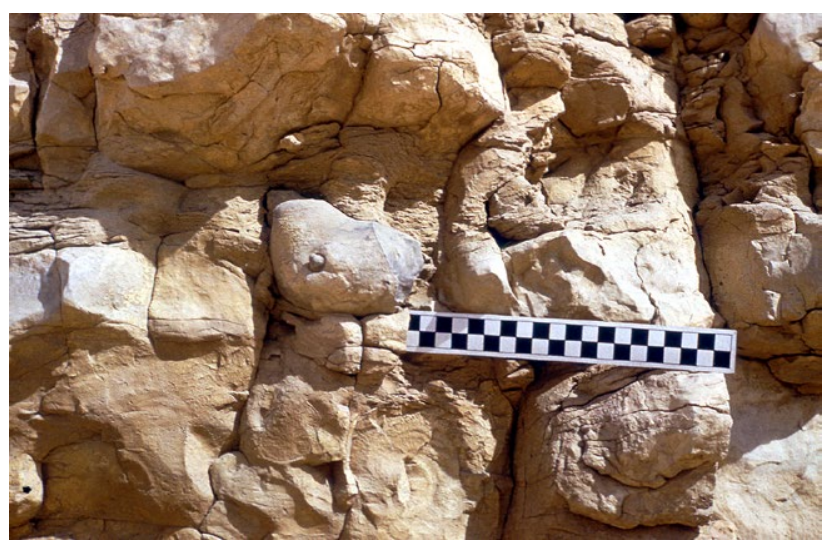

Fig. 5. Deir el-Bahari.

Flint nodules in the northern wall of the Valley.

Photo: B. Ginter.

el-Bahari Valley. These nodules could have also been easily prised out of the walls of erosion or tectonic cracks, such as those that cut through the ground of the Site 21. Having analysed the vertical diversification of the Theban limestone, the authors noticed certain differences in sizes and shapes of flint nodules. Within the levels above the altitude of $220 \mathrm{~m}$ a.s.l. one can encounter large specimens of dimensions ranging from a dozen or so up to more than $20 \mathrm{~cm}$ in diameter. They are irregular in shape, massive, sometimes nearly globular or oval-shaped (Fig. 5; Tawfik et al., 201I: 520).

The inventory of the series discussed here comprises 3064 knapped flint artefacts, including: 4 precores (o.1\%), 204 cores (6.7\%), 2575 flakes and chips (84.1\%), 64 blades (2.I\%), I2I unretouched Levallois tools $(3.9 \%)$ and 96 retouched tools (3.I\%). Such a composition is typical of sites where the entire flint processing cycle took place, starting from the preparation of precore forms, through the exploitation of the cores to obtain blanks, and ending with ultimate shaping of tools.

One of the characteristic traits of this assemblage is a great variability in manners of preparation and exploitation of cores. A significant though not very numerous group is represented by Levallois cores of various types (20 specimens - IO\%), with a predominance of classical single platform flake cores. The contribution of discoidal and sub-discoidal cores of the Mousterian type is also very visible (I6 specimens - 8\%). The most frequent are common flake cores, single and double platform ones, as well as cores with changed orientation ( 59 specimens $-30 \%$ ). The percentage of cores for flakes and blades is small (7 specimens $-3.5 \%$ ), whereas blade cores occur only very sporadically ( 2 specimens $-1 \%$ ). All of the groups of cores mentioned above bear clear traces of initial preparation preceding the process of exploitation. The latter was aimed mainly at production of flakes, and sometimes blades though to much smaller extent. Particularly with regard to Levallois cores, the initial treatment was usually very thorough, in some cases even meticulous. 


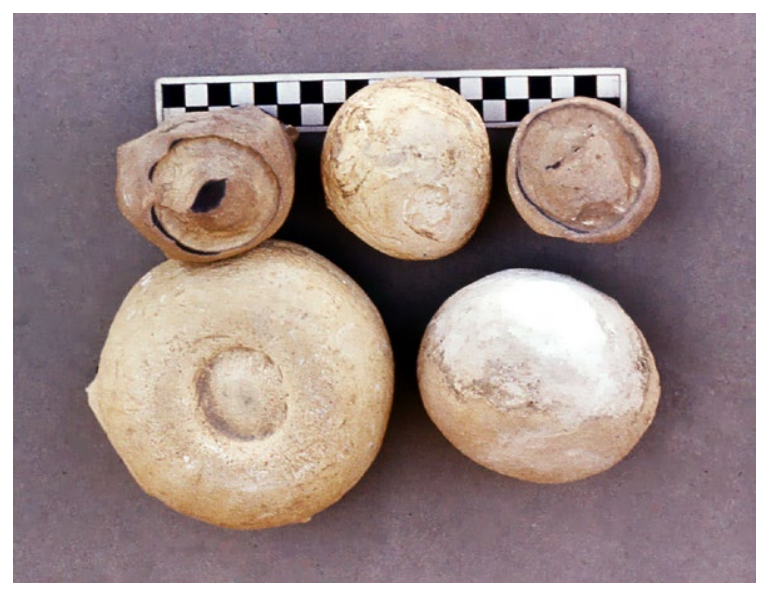

Fig. 6. Flint nodules. Photo: B. Ginter.

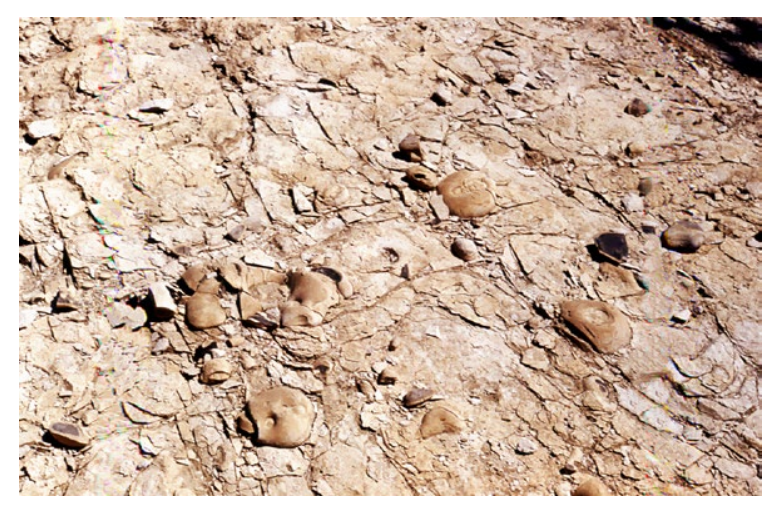

Fig. 7. Exposure of the Theban limestones with protruding chert nodules. Photo: B. Ginter.

A separate group of cores, the most numerous (9r specimens - 47\%), which we have decided to highlight in this paper, is represented by specimens showing no traces of any initial treatment, always made from globular or slightly flattened, usually very regular nodules, sometimes in a shape resembling a very thick lens or a strongly flattened cone (Fig. 6). These would have been found lying loose on a hard substrate constituted by eroded bedrock (Fig. 7) or within the limestone rubble of the slopes surrounding the valley. These cores are varied in shape, with dimensions from slightly exceeding $6 \mathrm{~cm}$ up to c. $12 \mathrm{~cm}$. In shape they resemble a concave-convex or flat-convex lens, and their flaking surface is usually formed by a single scar of a previously detached flake (Fig. 8: I-3). The striking platforms, sides and backs of such cores are covered with cortex and they wear no traces of any initial preparation preceding the exploitation. The exploitation always started from detaching a thick, more or less regular flake entirely cortical, using a hard hammer, and struck off at a selected point of the nodule circumference. Then the successive flake was detached, nearly always in the same direction as the previous 

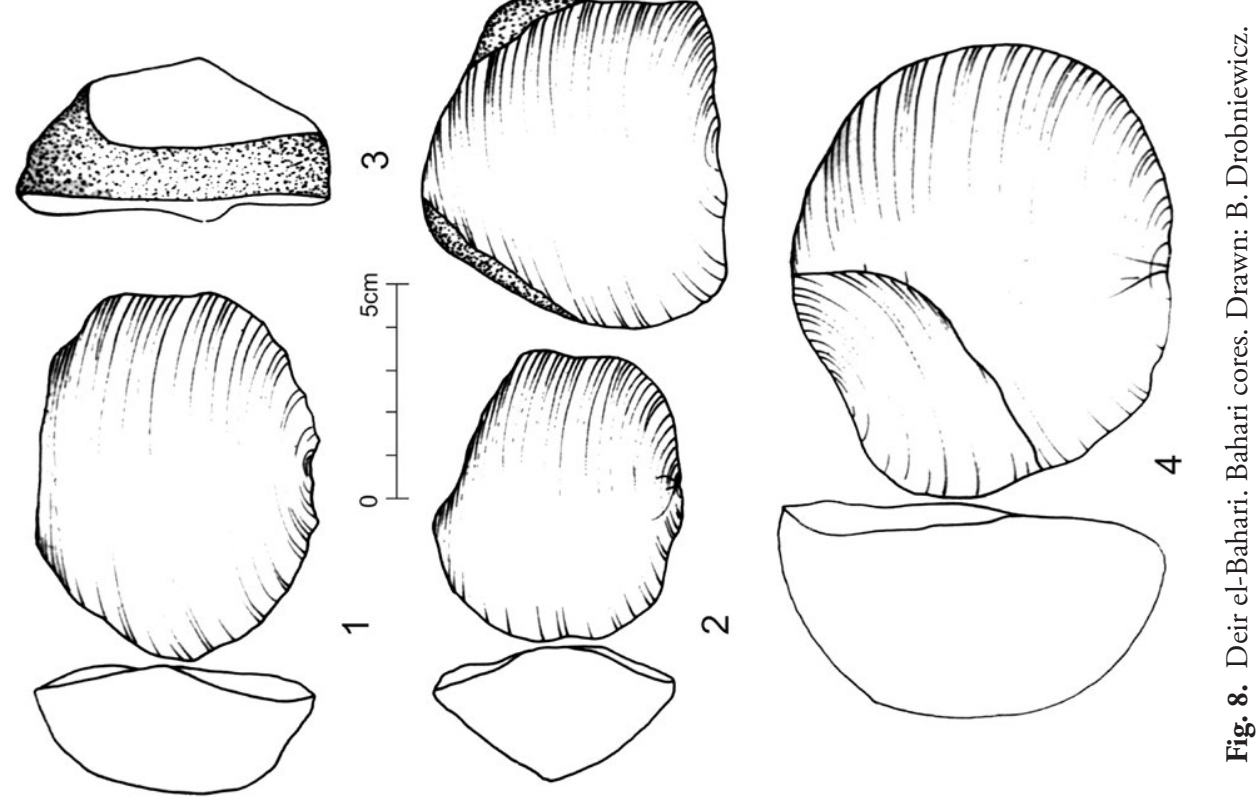

one. Afterwards one or two, at most, flakes were struck off, usually in the same direction as the former ones. Only sporadically was a different striking point on the nodule circumference selected (Fig. 8: 4). Thus, the technique of core processing was very simple, not to say primitive, and it aimed at obtaining no more than a few massive, thick flakes, rounded or oval-shaped, sometimes semi-circular, from one core. Due to its specific nature and distinctness from other currently identified manners of core processing, we called it the Bahari technique, after the Deir el-Bahari Valley.

There were recorded 2732 flakes and blades, being the result of preparation, exploitation and rejuvenation of cores. A significant role is played by I2I Levallois flakes, blades and points, with a considerable predominance of the former ones ( 98 specimens), the number of which is much greater than it could be anticipated based on the number of cores. At least a dozen or so Levallois flake cores were transformed in the course of exploitation or through retouching into specimens of a later series, six in particular, to which they were consequently included. The Levallois technical index is relatively low $(\mathrm{IL}=4.4)$. A further 153 flakes can be linked to the Levallois flint processing technique. They come from the advanced or final phases of forming the flaking surface. Another I23 flakes were detached from discoidal cores of the Mousterian type, supporting a hypothesis of their intense exploitation.

Within the debitage, common flakes prevail (2 078 specimens) over all other groups of waste products coming from all phases of the operational process. Relatively numerous are entirely cortical (472 specimens) or partly cortical flakes (I 442 specimens). 
Undoubtedly, this indicates a thorough initial preparation of cores before they were explored, starting from raw nodules processed on the spot, ending with obtaining desirable blanks. The initial treatment was employed less frequently in processing of a few blade cores, since amongst 64 identified blades almost all of them were covered with cortex to a smaller (38 specimens) or greater extent (Is specimens), while only nine blades were entirely cortical.

A separate group is constituted by 193 flakes detached from the above-mentioned Bahari cores. Amongst them, 49 specimens are entirely cortical flakes with usually strongly convex dorsal sides, which results from the type of employed nodules. In general, they are thick and massive, and their thickness sometimes exceeds $3 \mathrm{~cm}$ (Fig. IO: I, 4). A further 13 flakes were transformed into tools, whereas another dozen or so bear traces of tool treatment and are covered with patina, which indicates that they were used in later chronological periods. Most likely another few, possibly more than ten, artefacts were transformed with retouch to such an extent that their identification is impossible at the moment. Flakes bearing scars of previously detached specimens on their dorsal sides are clearly more numerous. There were recorded I44 examples of such artefacts, while a further $\mathrm{I} 3$ were transformed into tools, and another $\mathrm{I} 2$ have got younger scars of secondary tool treatment. About $90 \%$ of these flakes bear on their dorsal sides scars of specimens detached in the same direction (Fig. 9: I, 2; Fig. IO: 2). With regard to slightly more than IO\% of the artefacts, the scars on their dorsal sides are oblique or transverse to their detachment direction (Fig. IO: 3). Usually, they are covered with cortex on their entire circumference (Fig. 9: I, 2; Fig. IO: 2), sometimes the cortex is present only on $2 / 3$ or $1 / 2$ of their circumference (Fig. IO: 3 ). Diameters of flakes range from 6.2 to $11.5 \mathrm{~cm}$, while their thickness is between 2.0 and $2.5 \mathrm{~cm}$, in few cases up to $c .3 \mathrm{~cm}$. In total, there were identified 244 flakes of the Bahari type, including those transformed into tools, which gives an approximate number of three flakes per I core.

Retouched tools were represented by 96 specimens, which confronted with the number of I2I unretouched Levallois flakes, blades and points gives a relatively high Levallois typological index $(\mathrm{Ilty}=55.8)$. A scarce though significant group of artefacts is represented by Mousterian points (8 specimens), which occurred exclusively in the assemblage of this series. The most numerous are sidescrapers (47 specimens), mostly single ones (33 specimens): oblique, transverse and lateral. Significantly less frequent are bilateral sidescrapers (I3 specimens), including convergent specimens of the dejete type. Quite numerous are also denticulated pieces of various types ( 13 specimens), as well as notched tools ( 8 specimens), including Clactonian notches formed with single blows. Noteworthy is an occurrence of a single endscraper made from a flake and a single perforator made from an elongated flake. This toolset is complemented by four knife-like tools and four flakes and blades with marginal retouch, as well as two flakes with widespread surface retouch. A separate category is represented by adzes, namely 
The Middle Palaeolithic Assemblage with Bahari Technique from the Site 21b...
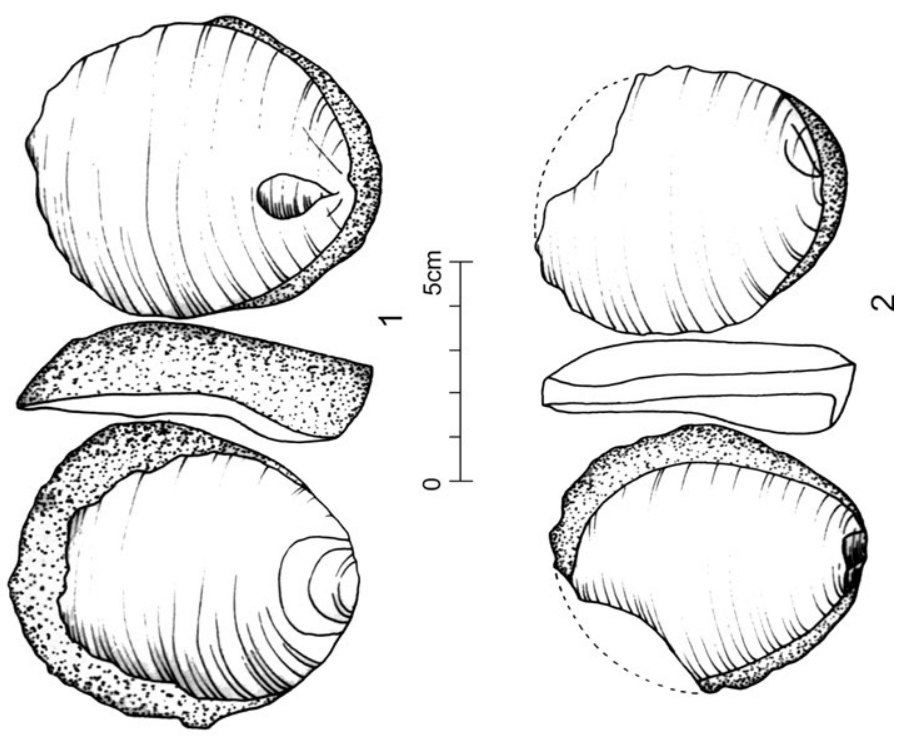

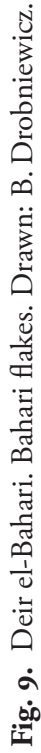
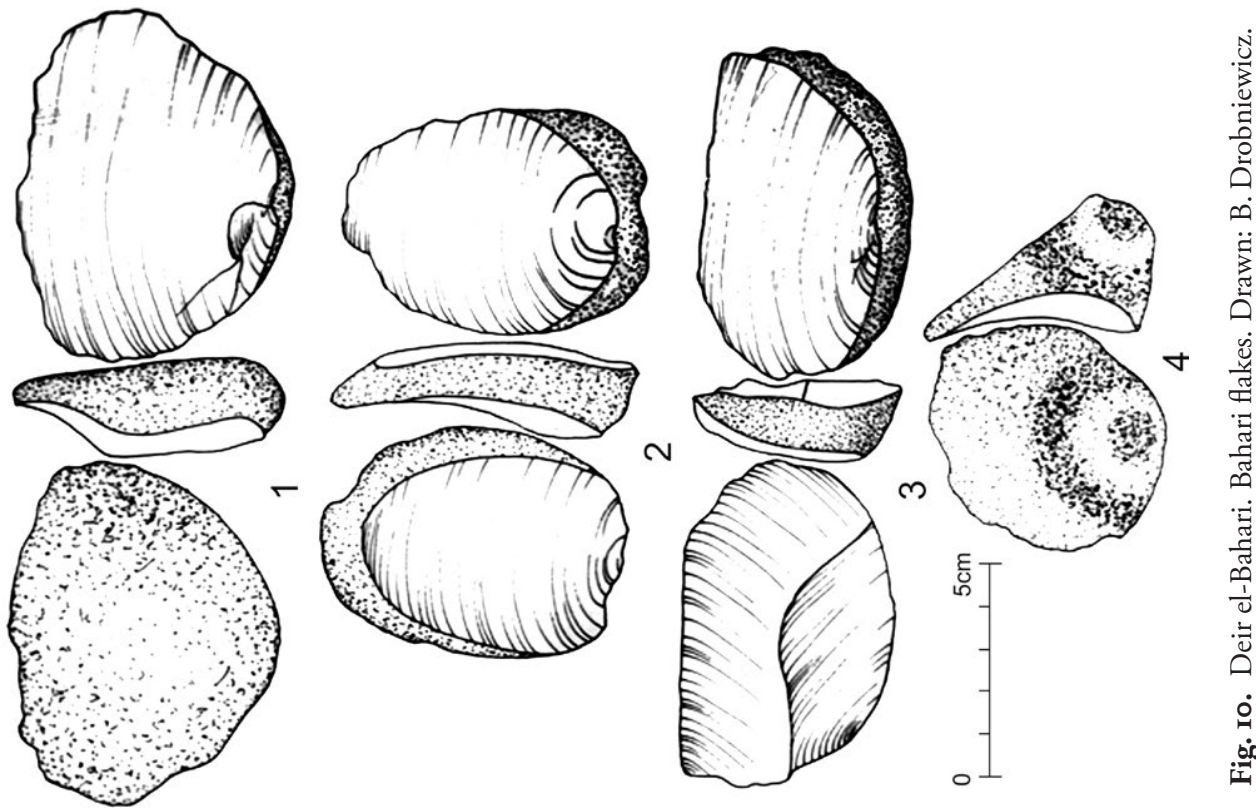


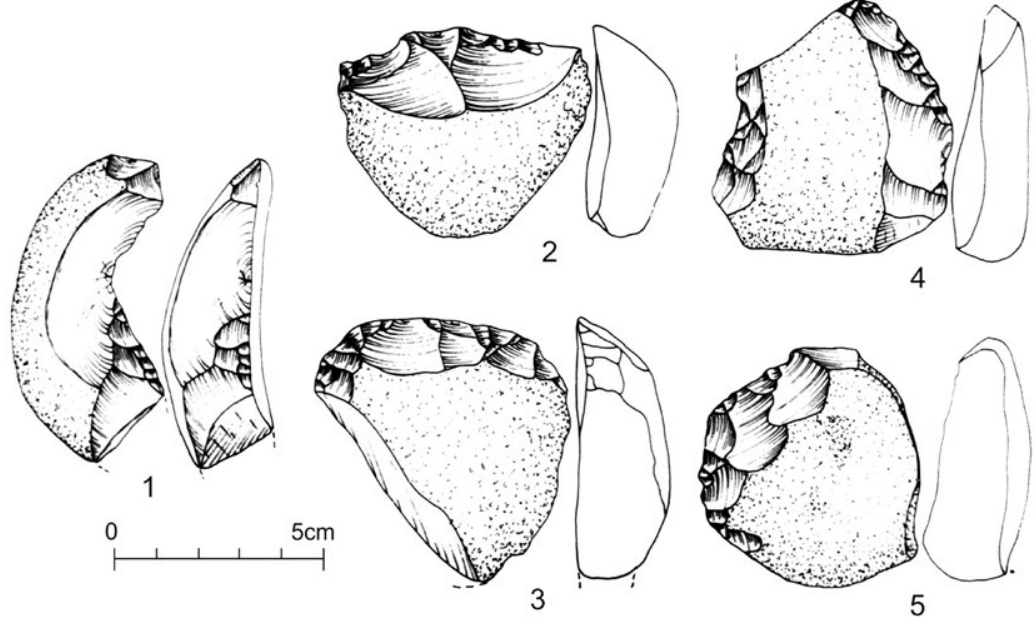

Fig. II. Deir el-Bahari. Retouched tools made from Bahari flakes. Drawn: B. Drobniewicz.

cleavers, and two small bifaces with unprepared, cortical bases, most likely associated with this series as well. It must be stressed that among the flakes there were no forms coming from bifacial treatment.

About $30 \%$ of the retouched tools of this series were made from flakes of the Bahari type. These were mostly sidescrapers (Fig. II: 3-5), notched (Fig. II: I) and denticulated pieces (Fig. II: 2). Having analysed these three groups of tools, a diversified frequency of the Bahari flakes and their semi products can be noticed. Thus, they were used for production of $70 \%$ of all denticulated pieces, $37 \%$ of notched tools and $25 \%$ of sidescrapers. This indicates various preferences of their makers, the reasons of which remain unknown.

\section{CONCLUSION}

The Middle Palaeolithic nature and consequently, chronology of the assemblage of the Series 2 from the Site $21 \mathrm{~b}$ is indicated unambiguously by several factors. On the one hand these are the technological features (Levallois cores and tools of various types, Mousterian discoidal cores and flakes from their processing), and on the other hand, the typological context of this series (Mousterian points, numerous sidescrapers, denticulated and notched pieces, lack of Upper Palaeolithic tools). This is also confirmed by the relatively older age of this assemblage when compared with those of the series 3 and 4 found at this site and representing Mousterian assemblages with Levallois 
The Middle Palaeolithic Assemblage with Bahari Technique from the Site 21b...

technique and cores of the Nubian type, which is undoubtedly evidenced by the state of preservation and the order of scars visible on dorsal sides of many artefacts. Until now, there are no unambiguous analogues for our assemblage amongst the Middle Palaeolithic industries from the territory of Egypt.

Elements of the Bahari technique are also encountered, though sporadically, at other sites in the Deir el-Bahari region, always accompanied by the Middle Palaeolithic forms. It is very likely that they occurred in locations where appropriate flint nodules were available. These nodules could have been exploited using the simple though effective technique that was discussed above. Employing such a technique suggests that the flintknappers and users of flint products were very creative and capable of adapting particular flint processing procedures to the available local raw materials.

\section{Translated by Agnieszka Klimek}

\section{REFERENCES}

Arcelin, A. 1869. Lettre à M. de Mortillet: L'âge de la pierre en Égypte. Revue Archéologique, Série 2: 136-407. Arcelin, A. I870. L'industrie primitive en Égypte et en Syrie. Mission Scientifique de Ministère de l'Instruction Publique I868-69. Raport au Ministre. Mâcon 9: 155-189.

Cottevieille-Giraudet, R. 1933. L'Égypte avant l'histoire. Bulletin de l'Institut Français d'Archéologie Orientale: 3 : $\mathrm{I}-\mathrm{I} 68$.

Debono, F. 1972. Gisements préhistoriques de la Montagne thébaine. Graffiti de la Montagne thébaine: I: 3. Le Caire.

Drobniewicz, B., Ginter, B. and Kozłowski, J. K. 1976. Topographie préhistorique du cirque de Deir el-Bahari. Deir el-Bahari I. Zeszyty Naukowe Uniwersytetu Jagiellońskiego. Prace Archeologiczne 24: II-26.

Drobniewicz, B. and Ginter, B. 2019. Deir el-Bahari, Upper Egypt. In M. Chłodnicki and P. L. Polkowski (eds), When the Sahara was green. Polish archaeological research on the prehistory of North Africa, I05-I08. Poznań.

Heflik, W. and Kozłowski, J. K. 1977. Remarques sur la caractéristique géologique, minéralogique et pétrographique des sédements du Nil dans le Cirque de Deir el-Bahari. Deir el-Bahari 2. Zeszyty Naukowe Uniwersytetu Jagiellońskiego. Prace Archeologiczne 25: 7-30.

Marks, A. E. 1968a. The Mousterian Industries of Nubia. In F. Wendorf (ed.), The Prehistory of Nubia I: I94-314. Dallas, Texas.

Marks, A. E. 1968b. The Khormusan: An Upper Pleistocene Industry in Sudanese Nubia. In F. Wendorf (ed.), The Prehistory of Nubia r: 315-39r. Dallas, Texas.

Pitt Rivers, A. 1882. On the discovery of chert implements in stratified gravel in the Nile Valley near Thebes. The Journal of the Anthropological Institute of Great Britain and Ireland II: 382-400.

Said, R. 1975. The geological evolution of the River Nile. In F. Wendorf and A. E. Marks (eds), Problems in Prehistory Northern Africa and the Levant, I-44. Dallas, Texas.

Said, R., Wendorf, F. and Schild, R. 1970. The Geology and Prehistory of the Nile Valley in Upper Egypt. Archaeologia Polona I2: 19-42. 
$78 \mid$ Barbara Drobniewicz and Bolestaw Ginter

Sanford, K. S. and Arkell, W. J. 1933. Palaeolithic Man in the Nile Valley in Nubia and Upper Egypt. The University of Chicago Oriental Institute Publications 17.

Schweinfurth, G. 1903. Steinzeitliche Forschungen in Ober Ägypten. Zeitschrift für Ethnologie 35: 798-838.

Tawfik, H. A., Zahran, E. K., Abdel-Hammed, A. T. and Maejima, W. 20II. Mineralogy, petrography, and biostratigraphy of the Lower Eocene succession at Gebel El-Qurn, West Luxor, Southern Egypt. Arabian Journal of Geosciences 4: 520. 